\title{
APPLICATION OF THE "SIX SIGMA" METHOD FOR THE ANALYSIS OF THE IMPROVEMENT OF THE ENVIRONMENTAL AIR QUALITY \\ PARAMETERS AT THE MUNICIPALITY OF BUCHAREST, BY MONITORING THE POLLUTANCES OF NOx POLLUTANTS
}

\author{
ION DURBACĂ, NICOLETA SPOREA*, DANA-CLAUDIA FARCAȘ-FLAMAROPOL, \\ ELENA SURDU \\ "Politehnica" University of Bucharest, Spl. Independenței street, 313, Bucharest, Romania \\ e-mail: ion.durbaca@yahoo.com,nsporea@yahoo.com, claudia.flamaropol@gmail.com, \\ elena.surdu@yahoo.com
}

\begin{abstract}
This paper analyzes the improvement of ambient air quality indicators by monitoring the $\mathrm{NO}_{x}$ concentration in one of the most polluted areas of Bucharest, using the statistical method "SIX SIGMA" $(6 \sigma)$. By applying the methodology of this statistical approach, the aim is to reduce nonconformities within the specified limits (according to the standards and legislative norms in force) and respectively, to ensure maximum efficiency $(99,99 \%)$, equivalent to a yield of 3.4 defects per million opportunities (DPMO). As high concentrations of air pollutants have a major impact on human health, the most harmful effect has been found to be caused by nitrogen dioxide $\left(\mathrm{NO}_{2}\right)$, mainly from ground-level ozone. Using the " $\sigma \sigma$ " method, the optimal solutions for eliminating non-conformities and implicitly for reducing the $\mathrm{NO}_{2}$ concentration and ensuring the improvement of the ambient air quality can be identified.
\end{abstract}

Keywords: Six Sigma, air quality, air pollutant, efficiency.

\section{INTRODUCTORY CONSIDERATIONS}

At present, air pollution has proven to be one of the greatest dangers from an environmental, human health and ecosystem perspective, attracting negative effects not only locally or nationally, but also at European and global level (European Environment Agency).

At the level of large urban agglomerations, including the city of Bucharest, one of the major pollutants is road transport, as the main responsible for the production of nitrogen oxides $\left(\mathrm{NO}_{\mathrm{x}}\right.$ - extremely harmful pollutants), but also suspended particles (PM) (Brue, 2002).

The Great Metropolis - Bucharest is one of the most polluted cities in Europe and is in the process of infringing with the European Environment Commission for constant exceedances of the quantities of fine moving particles in the air (PM10, PM2.5), but also for the inability to monitor air quality according to the law.

Currently, the National Air Quality Monitoring Network (RNMCA) includes 148 continuous air quality monitoring stations, equipped with automatic equipment for measuring the concentrations of the main air pollutants: sulfur dioxide $\left(\mathrm{SO}_{2}\right)$, nitrogen oxides $\left(\mathrm{NO}_{\mathrm{x}}\right)$, carbon monoxide $(\mathrm{CO})$, ozone $\left(\mathrm{O}_{3}\right)$, suspended particles (PM10 and $\mathrm{PM} 2.5)$ etc. The air quality in each monitoring station is represented by suggestive quality indices, established based on the values of the concentrations of the main air pollutants measured (Bejan et al., 2009; Alpopi, 2008; Vişan et al., 2000; Crișan et al., 2017; Kifor, 2006).

Due to the identification by measurement of high concentrations of nitrogen dioxide $\left(\mathrm{NO}_{2}\right)$ in the six existing monitoring stations in Bucharest, the statistical approach "Six Sigma" was addressed in order to analyze the improvement of ambient air quality parameters by including preventive and corrective measures to reduce the $\mathrm{NO}_{2}$.

https://doi.org/10.24264/icams-2020.III.5 
Application of the New Statistical Approach "Six Sigma" for the Analysis of the Improvement of the Air Quality Parameters at the Level of Bucharest, by Monitoring the $\mathrm{NO}_{x}$ Concentrations from the Emissions of Air Pollutants

\section{DEFINITION OF THE STATISTICAL METHOD "SIX SIGMA"}

The novelty of this statistical method "Six Sigma", typical of quality engineering, is the possibility of its application at the level of many organizations, regardless of their specifics (Moțoiu, 1994).

So, starting with the emergence of the concept of "zero defects", which was the starting point in the creation of the statistical method "Six Sigma" for Motorola in 1986 by Bill Smith and then continuing with its application to other top companies (General Electric, Honeywell International, ABB, Lockheed Martin, Polaroid, Sony, Honda, American Express and Solectron), the application of this statistical approach has been launched in many organizations around the world, most of which can prove the role of a pivotal element of the "Six Sigma" method to their success (Pande, 2008; Pande et al., 2009; Durbacă and Sporea, 2012; Durbacă, 2015).

By using the results of concrete assessments of quality characteristics specific to the concentration of nitrogen dioxide $\left(\mathrm{NO}_{2}\right)$ measured in the six existing monitoring stations in Bucharest, the paper aims as a methodology specific to the statistical approach Six Sigma (" $6 \sigma$ "), lead implicitly to improvements in the performance, efficiency and quality of the ambient air, as well as to the reduction of defects / nonconformities corresponding to the values measured within the specified limits (Lower limit of specification, LIS $=15 \mu \mathrm{g} / \mathrm{m}^{3}$ and Upper limit of specification, LSS $=40$ $\mu \mathrm{g} / \mathrm{m}^{3}$ ), according to the provisions of Law no. 104 of June 15, 2011.

In Figure 1, the performances of the " $6 \sigma$ " method are highlighted graphically, by comparison with the " $3 \sigma$ " method, taking into account the standard deviation " $\sigma$ " which represents the basic metric in the statistical analysis of the data of some evaluated / measured characteristics, respectively the value of the variable showing the distribution of the output characteristic of the process.

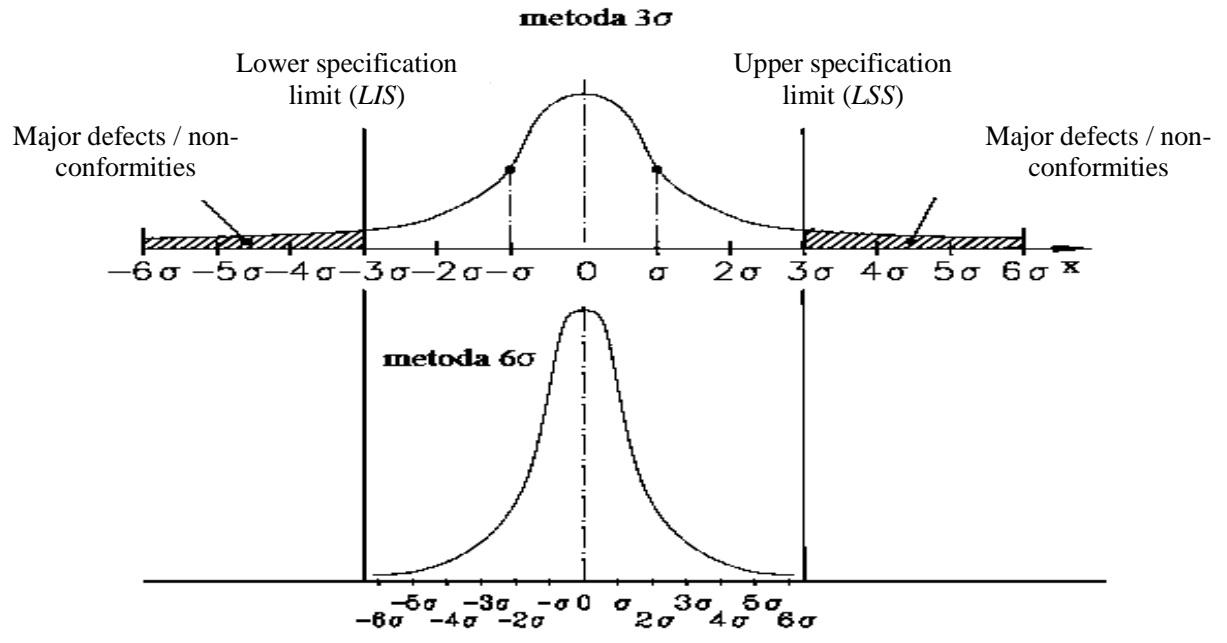

Figure 1. Performance of the "Six Sigma" method (Durbacă and Sporea, 2012)

A higher value for sigma $(\sigma)$ indicates a more stable process, with a lower risk for defective events (rejects / major nonconformities) and lower costs, respectively. 


\section{DESCRIPTION OF THE APPLICATION}

The step-by-step approach of the specific phases of the "Six Sigma" method (DMAIC) is considered: Defining opportunities / quality problems; Measuring current performance levels; Analysis of the causes underlying the non-conformities / defects; Improving performance; Control performance (Durbacă and Sporea, 2012).

To obtain the best results, an analysis of the daily values of $\mathrm{NO}_{2}$ concentrations $\left[\mu \mathrm{g} / \mathrm{m}^{3}\right]$ was performed measured at the six continuous air quality monitoring stations in Bucharest (S1 - Lacul Morii; S2 - Titan; S3 - Mihai Bravu; S4 - Berceni; S5 - Camp Road; S6 - Military Circle) for a period of 20 calendar days (12.08.2020 - 31.08.2020).

Following the brainstorming analysis at a meeting of a group of specialists in the field, it was decided that the daily values of $\mathrm{NO}_{2}$ concentrations $\left[\mu \mathrm{g} / \mathrm{m}^{3}\right]$ measured at station S3 - Mihai Bravu, having the highest values, to be subjected to the application of the Six Sigma methodology.

To represent the probability density graph in the case of a normal distribution (Gauss) the results corresponding to the strategy for accurately detecting non-compliant $\mathrm{NO}_{2}$ concentrations $\left[\mu \mathrm{g} / \mathrm{m}^{3}\right]$, of their quantification and elimination, it is necessary to go through the following methodological procedure (Durbacă and Sporea, 2012):

a) ascending order of the string of 20 measured values $X_{i}(i=1, \ldots \ldots, 20)$ of the quality characteristic / $\mathrm{NO}_{2}$ concentration $\left[\mu \mathrm{g} / \mathrm{m}^{3}\right]$, thus:

26,$29 ; 30,04 ; 34,93 ; 37,09 ; 37,18 ; 37,23 ; 38,30 ; 38,41 ; 38,69 ; 44,18 ; 45,70 ; 48,72$; 56,$38 ; 57,28 ; 58,94 ; 60,10 ; 61,10 ; 62,19 ; 64,15 ; 69,02$.

b) notation of the minimum value $\mathrm{X}_{\min }$ and respectively, maximum $\mathrm{X}_{\max }$ of the ascending ordered string:

$X_{\min }=26,29\left[\mu \mathrm{g} / \mathrm{m}^{3}\right] ; X_{\max }=69,02\left[\mu \mathrm{g} / \mathrm{m}^{3}\right]$.

c) determining the amplitude of the string:

$R=X_{\max }-X_{\min }=69,02-26,29=42,73\left[\mu \mathrm{g} / \mathrm{m}^{3}\right]$.

d) determining the number of classes $K$ of the sequence of ordered values, with Sturges formula (Durbacă and Sporea, 2012):

$K=1+3,22 \lg n=1+3,22 \lg 20 \approx 5$.

e) determining the amplitude of the class, $\delta$ :

$\delta=R / K=42,73 / 5=8,54$.

f) completing the ordered values according to the previously determined classes, in Table 1:

Table 1. Values ordered by classes

\begin{tabular}{ccccc}
\hline K1 & K2 & K3 & K4 & K5 \\
\hline 26,29 & 37,18 & 38,69 & 56,38 & 61,10 \\
30,04 & 37,23 & 44,18 & 57,28 & 62,19 \\
34,93 & 38,30 & 45,70 & 58,94 & 64,15 \\
37,09 & 38,41 & 48,72 & 60,10 & 69,02 \\
\hline
\end{tabular}

g) determining the grouping intervals corresponding to the value classes and respectively, average value $\bar{X}$ (v. Table 2 ): 
Application of the New Statistical Approach "Six Sigma" for the Analysis of the Improvement of the Air Quality Parameters at the Level of Bucharest, by Monitoring the $\mathrm{NO}_{x}$ Concentrations from the Emissions of Air Pollutants

Table 2. Grouping intervals corresponding to value

\begin{tabular}{cccccccc}
\hline No. & $\begin{array}{c}\text { Grouping } \\
\text { interval }\end{array}$ & Centered & \multicolumn{4}{c}{ Frequency } \\
& $x_{i} \div x_{i+j}$ & $\boldsymbol{x}_{\boldsymbol{i c}}$ & $\boldsymbol{a}_{\boldsymbol{i}}$ & $\boldsymbol{f}_{\boldsymbol{i}}$ & $\boldsymbol{A}_{\boldsymbol{i}}$ & $\boldsymbol{F}_{\boldsymbol{i}}$ & $\boldsymbol{X}_{\boldsymbol{c}} \boldsymbol{f}_{\boldsymbol{i}} \boldsymbol{.}$ \\
\hline 1 & $26,29 \div 34,83$ & 30,56 & 2 & 0,10 & 2 & 0,10 & 3,056 \\
2 & $34,93 \div 43,47$ & 39,20 & 7 & 0,35 & 9 & 0,45 & 13,720 \\
3 & $44,18 \div 52,72$ & 48,45 & 3 & 0,15 & 12 & 0,60 & 7,267 \\
4 & $56,38 \div 64,92$ & 60,65 & 7 & 0,35 & 19 & 0,95 & 21,227 \\
5 & $69,09 \div 69,02$ & 0 & 1 & 1,05 & $\mathbf{2 0}$ & $\mathbf{1 , 0 0}$ & 0,000 \\
& $\Sigma$ & & $\mathbf{2 0}$ & $\mathbf{1 , 0 0}$ & - & - & $\mathbf{4 5 , 2 7}$ \\
\hline
\end{tabular}

h) determination of the mean square error $\sigma$, with the relation:

$\sigma=\sqrt{\frac{\sum_{i=1}^{n}\left(X_{i}-\bar{X}\right)^{2}}{n-1}}=12,806$

i) determining the limits of specifications $\backslash$ (lower, LIS* and upper, $L S S^{*}$ ) corresponding to the actual level of performance $6 \sigma=76,836$ :

$L I S^{*}=\bar{X}-3 \sigma=45,27-3 \cdot 12,806=6,852$;

$L S S^{*}=\bar{X}+3 \sigma=45,27+3 \cdot 12,806=83,688$.

j) the representation of the normal distribution curve, related to the values specific to the quantification of the maximum performance (corresponding to level $6 \sigma$, equivalent to 3,4 defects per 1 million opportunities), via the normal Gauss distribution function, $f(x)$ and the MathCAD program (see Figure 2).

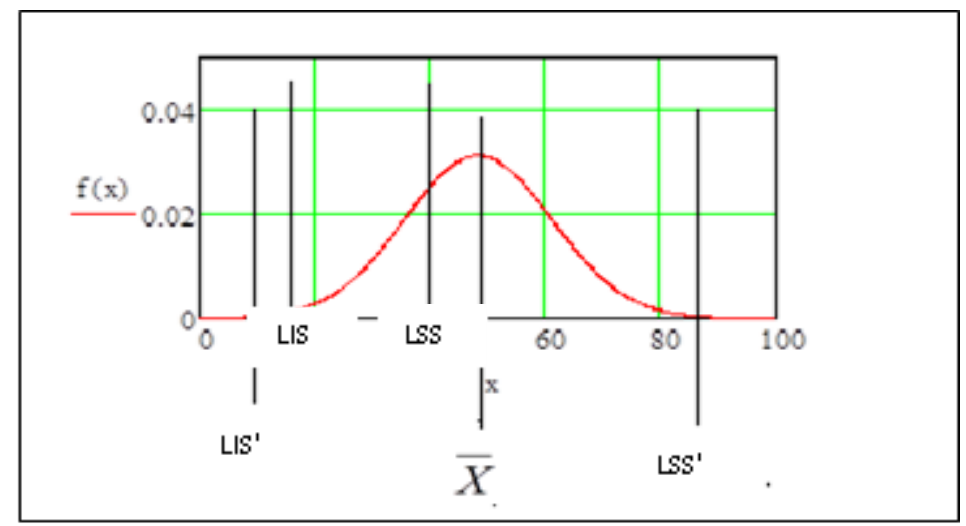

Figure 2. Gauss normal distribution curve

According to the graphical representation of the function $f(x)$ in Figure 2, corresponding to the distribution of the measured values of the analyzed quality characteristic, in relation to their average value, it follows that the graphical distribution of the "Gauss's bell" is between the limits of specifications (LIS* and LSS*) previously determined with relationships (5) and (6). Such a distribution characterizes a real level of maximum performance " $6 \sigma$ ”, equivalent to 3,4 defects per 1 million opportunities

https://doi.org/10.24264/icams-2020.III.5 


\section{RESULTS AND DISCUSSIONS}

Considering that in the analyzed case the condition is fulfilled: $6 \cdot \sigma>\mathrm{R}$, this would correspond to the need to improve the quality and, respectively, to take measures to help to rigorously frame the values of $\mathrm{NO}_{2}$ concentrations between the limits of the LIS and LSS specifications and respectively, eliminating values that do not fall within these limits. But nevertheless, the graphical representation of the normal Gaussian distribution function $f(x)$, in Figure 2 above, confirms the permissiveness of extending the range of measured values between the specification limits $L I S^{*}$ and $L S S^{*}$, which attests to the achievement of the efficiency index of 3,4 defective parts per million opportunities (DPMO), corresponding to an efficiency of $99,9997 \%$ and synonymous with the successful completion of the quality improvement project.

From the calculation of the capability index of the quality improvement process, $\mathrm{C}_{p}$ results (Durbacă, 2017):

$C_{p}^{*}=\frac{\text { LSS } * \text { LIS } *}{6 \sigma}=1,00$.

In this case, for which $C_{p} *<1,33$, the improvement process may become efficient under certain conditions, but careful supervision is required (Durbacă, 2017).

\section{CONCLUSIONS}

By applying the statistical method "Six Sigma" at the level of any organization regardless of the activity profile, it is possible to respond to the purpose function, defined by the improvement of the quality of the analyzed entities. Although it is a method based on mathematical statistics, "Six Sigma" does not offer a difficult tool to use and thus represents, a guaranteed success for such organizations that aim to achieve outstanding results and ensure superior levels of performance.

Therefore, the "Six Sigma" statistical method is equally addressed to all organizations for improving performance, efficiency and quality of entities (products, processes, services, resources, environmental factors, etc.), as well as to reduce defects / non-conformities within the specified limits, by ensuring maximum stability and efficiency.

\section{REFERENCES}

Alpopi, Cr. (2008), "The effects of urban agglomeration on the environment, in the magazine", Economia series Management, 11(2), 12-20.

Bejan, M., Rusu, T. and Bălan, I. (2009), "The effects of air pollution due to car transport activity", AGIR Bulletin, 4, October-December, 192 - 199.

Brue, Gr. (2002), Six Sigma for Managers, McGraw-Hill, New York.

Crișan, H.G., Crișan, O.A., Lakatos, E.S. and Scurtu, I.L. (2017), "Aspects regarding the effects of vehicle pollution on the environment - Case study", XVII International - multidisciplinary Conference "Professor Dorin Pavel - founder of Romanian hydropower", Sebeș.

Durbacă, I. (2015), "New Statistical Approach "Six Sigma" as a Solution for Improving Plastic Quality Products", Materiale Plastice, 52(1), 43-47.

Durbacă, I. (2017), "Engineering and quality control «Six Sigma»", Guide to applied works - For students" use, Printech Publishing House, Bucharest, ISBN 978-606-23-0728-8, 142 pages, CNCSIS Code 54, BN Quota - 62.

Durbacă, I. and Sporea, N. (2012), Engineering, management and quality assurance, Bucharest, Printech Publishing House.

Kifor, C.V. (2006), Quality engineering. Improving 6 Sigma, "Lucian Blaga” University of Sibiu Publishing House.

https://doi.org/10.24264/icams-2020.III.5 
Application of the New Statistical Approach "Six Sigma" for the Analysis of the Improvement of the Air Quality Parameters at the Level of Bucharest, by Monitoring the $\mathrm{NO}_{x}$ Concentrations from the Emissions of Air Pollutants

Moțoiu, R. (1994), Quality Engineering, Chiminform Data S.A. Publishing House, Bucharest.

Pande, S.P. (2008), The Six Sigma Leader. How Top Executives Will Prevail in the 21st Century, McGrawHill Professional.

Pande, S.P., Neuman, P.R. and Cavanagh, R.R. (2009), "Six Sigma”, How GE, Motorola and other top companies improve their performance, ALL Publishing House, Bucharest.

Vişan, S., Angelescu, A. and Alpopi, C. (2000), Environment. Pollution and protection, Bucharest, Economic Publishing House.

*** European Environment Agency, “Air pollution”, https://www.eea.europa.eu/themes/air, Date las accessed: 30.06 .2020 